\title{
Wpływ metody cięcia na właściwości stalowej krawędzi ciętej
}

\section{The cutting method influence on properties of cut edge}

\section{Streszczenie}

W artykule opisano wpływ procesu cięcia na jakość krawędzi ciętej ze szczególnym uwzględnieniem szerokości strefy wpływu ciepła, rozkładu twardości od krawędzi ciętej oraz zmiany struktury od krawędzi ciętej w głąb materiału. Określone właściwości opisano dla cięcia plazmowego, laserowego, tlenowego oraz mechanicznego papierami ściernymi.

\section{Abstract}

The paper describes the impact of the cuts on the quality of the cut edges with particular reference to the width of the HAZ, hardness distribution from the edge of the cut and changes in the structure of the edge cut into the material. The specific characteristics described for plasma, laser beam, oxygen cutting and also for mechanical cutting with the use of abrasive papers.

\section{Wstęp}

Rozwój procesów spajania i nierozłączny z tym wzrost wymagań jakościowych przy wytwarzaniu konstrukcji spawanych pociąga za sobą konieczność rozwoju technik pokrewnych wpływających bezpośrednio na jakość tych konstrukcji, a w konsekwencji na bezpieczeństwo techniczne wyrobu. Dzisiejszym konstrukcjom stawiany jest jeden główny cel, tzn. muszą być bezpieczne dla użytkownika i środowiska. Środkiem zapewniającym stworzenie jednolitego systemu bezpieczeństwa urządzeń i konstrukcji jest ujednolicenie prawa, czyli jego harmonizacja. W przypadku wytwarzania konstrukcji i urządzeń technicznych harmonizacja przepisów polega na wprowadzaniu w krajach Unii Europejskiej norm zharmonizowanych, które są obowiązujące w państwach członkowskich.

Wstępnym i bardzo istotnym czynnikiem decydującym o jakości połączeń spawanych jest jakość przygotowania elementów do spawania, a głównie jakość krawędzi ciętej formującej geometrię rowka spawalniczego.Wprowadzona 1 lipca 2012 r. zharmonizowana norma PN-EN 1090-2 zaleca sprawdzanie przydatności procesów cięcia. Wymaganą klasę jakości powierzchni ciętej sprawdza się na próbkach o długości nie mniejszej niż $200 \mathrm{~mm}$. Próbki do wycinania ostrych naroży

Dr inż. Ryszard Pakos - Zachodniopomorski Uniwersytet Technologiczny w Szczecinie. i cięcia zakrzywionego powinny być skontrolowane pod względem jakości krawędzi wg norm dotyczących cięcia prostego. Jakość powierzchni po cięciu określana jest zgodnie z EN ISO 9013. Wymagania dotyczące jakości powierzchni cięcia w zależności od klasy wykonania konstrukcji przedstawiono $w$ tablicy I.

Jeśli jest wymagane badanie twardości, to twardość powierzchni brzegów stali węglowej po cięciu powinna być zgodna z tablicą II.

Tablica I. Jakość powierzchni po cięciu w zależności od klasy konstrukcji [5]

Table I. Surface quality after cutting for structure quality class [5]

\begin{tabular}{|c|c|c|}
\hline $\begin{array}{c}\text { Klasa } \\
\text { konstrukcji }\end{array}$ & $\begin{array}{c}\text { Tolerancja prostopadłości } \\
\text { lub nachylenia, u }\end{array}$ & $\begin{array}{c}\text { Średnia wysokość profilu } \\
\text { Rz 5 }\end{array}$ \\
\hline EXC2 & zakres 4 & zakres 4 \\
\hline EXC3 & zakres 4 & zakres 4 \\
\hline EXC4 & zakres 3 & zakres 3 \\
\hline
\end{tabular}

Tablica II. Dopuszczalna maksymalna twardość HV10 [5] Table II. Accepted maximum hardness HV10 [5]

\begin{tabular}{|l|c|c|}
\hline \multicolumn{1}{|c|}{ Normy wyrobów } & Gatunek stali & $\begin{array}{c}\text { Twardość } \\
\text { maksymalna }\end{array}$ \\
\hline EN 10025-2 do -5 & S235 do S460 & 380 \\
\hline EN 10210-1, EN 10219-1 & & \multirow{2}{*}{450} \\
\hline EN 10149-2, EN 10149-3 & S260 do S700 & \\
\cline { 1 - 2 } EN 10025-6 & S460 do S690 & \\
\cline { 1 - 2 } &
\end{tabular}

Uwaga: Te wartości, zgodnie z EN ISO 15614-1, stosuje się do gatunków stali wymienionych w ISO/TR20172. 
W tym przypadku procesy, które moga powodować lokalne utwardzenia (cięcie termiczne, przecinanie, wykrawanie), powinny mieć sprawdzoną przydatność. Jeśli to konieczne - w celu sprawdzenia wymagań dotyczących twardości powierzchni brzegów po cięciu stosuje się podgrzewanie.

Jeśli nie ustalono inaczej, to sprawdzenie przydatności procesów cięcia wykonuje się w następujący sposób:

- z wyrobu konstrukcyjnego, który jest najbardziej podatny na utwardzenie miejscowe, pobiera się cztery próbki do badań;

- na każdej próbce przeprowadza się cztery badania twardości wg EN ISO 6507 w miejscach najbardziej narażonych na utwardzenie.

Wybór metody cięcia zależy od wymagań jakościowych oraz możliwości technicznych i finansowych wytwórcy. Dokonując wyboru metody cięcia, należy brać pod uwagę jakość krawędzi ciętej, tolerancje wymiarowe, prędkość cięcia oraz kształt wycinanych elementów. Obecnie producenci oferują coraz więcej urządzeń do cięcia, przy zróżnicowanych kosztach gwarantujących zadowalającą jakość krawędzi ciętych.

W praktyce przemysłowej dominują trzy podstawowe metody cięcia, tj. tlenowo-płomieniowe, plazmowe i cięcie laserowe. Ponadto wytwórcy szczególnie w procesie ukosowania krawędzi - wykorzystują metody mechaniczne z użyciem odpowiednich papierów ściernych.

Cięcie tlenowo-gazowe jest w dalszym ciągu jedną z podstawowych metod cięcia, lecz ze względu na ograniczenia cieplno-metalurgiczne jest stosowane w procesach cięcia czystego żelaza oraz stali niestopowych i niskostopowych. Na możliwość zastosowania i jakość procesu cięcia tlenowego wpływa głównie skład chemiczny materiału podstawowego, czystość tlenu tnącego, stan powierzchni ciętego materiału, zastosowany gaz palny płomienia podgrzewającego oraz temperatura przecinanego materiału.

Cięcie plazmowe to metoda konkurencyjna dla cięcia tlenowo-gazowego, będąca obecnie technologią wiodącą, głównie dzięki wysokiej wydajności i niskim kosztom eksploatacyjnym, a także możliwości przecinania materiałów o większych grubościach (do ok. $150 \mathrm{~mm}$ ) [4]. Cięcie plazmowe stosowane jest do wszystkich rodzajów materiałów przewodzących prąd elektryczny, jak: stal, aluminium, żeliwo czy miedź, a przy zastosowaniu głowic z łukiem niezależnym (wewnętrznym) umożliwia cięcie materiałów niemetalicznych (tworzywa sztuczne, szkło, guma itp.).

Cięcie laserowe jest procesem o ugruntowanej obecnie pozycji, przede wszystkim do precyzyjnego cięcia blach cienkich, tj. do ok. $5 \mathrm{~mm}$ oraz do cięcia blach grubych $(10 \div 25 \mathrm{~mm})$, z wykorzystaniem laserów dużej mocy (przeważnie powyżej 4 kW) [1, 3, 4].

Zaletą technologii cięcia laserowego blach grubych jest większa dokładność cięcia oraz lepsza jakość powierzchni cięcia i mniejsze odkształcenia.
Metoda ta umożliwia cięcie większości materiałów, np. metali, tworzyw sztucznych, szkła czy materiałów izolacyjnych i daje możliwość wycinania otworów w przestrzennie ukształtowanych elementach kabin,

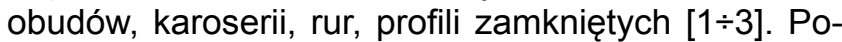
stęp w rozwoju generatorów promieniowania laserowego i konstrukcji przecinarek laserowych jest bardzo duży i dlatego należy śledzić tendencje rozwojowe tych urządzeń, aby w pełni wykorzystać ich zalety i możliwości.

\section{Badania własne}

Celem badań własnych było określenie szerokości strefy wpływu ciepła, rozkładów twardości od czoła krawędzi ciętej oraz zmian strukturalnych, na próbkach wyciętych ze stali S690QL grubości $16 \mathrm{~mm}$.

Próbki do badań pobrano z profili płaskich, wycinanych w zakładzie produkcyjnym (rys. 1).

Proces cięcia przeprowadzono na stanowiskach wyposażonych w następujące urządzenia:

- Portal ESAB SUPRAREX SXE - PZ 4000, do cięcia plazmowego i tlenowego;

- Bystar 4020 ( $\operatorname{moc} 4,4$ kW), do cięcia laserowego;

- KMW Krüger Maschinenbau, KFIV-2150, do obróbki ściernej.

Wszystkie procesy cięcia wykonano przy optymalnych parametrach dla badanej grubości ciętego materiału na długości $200 \mathrm{~mm}$.

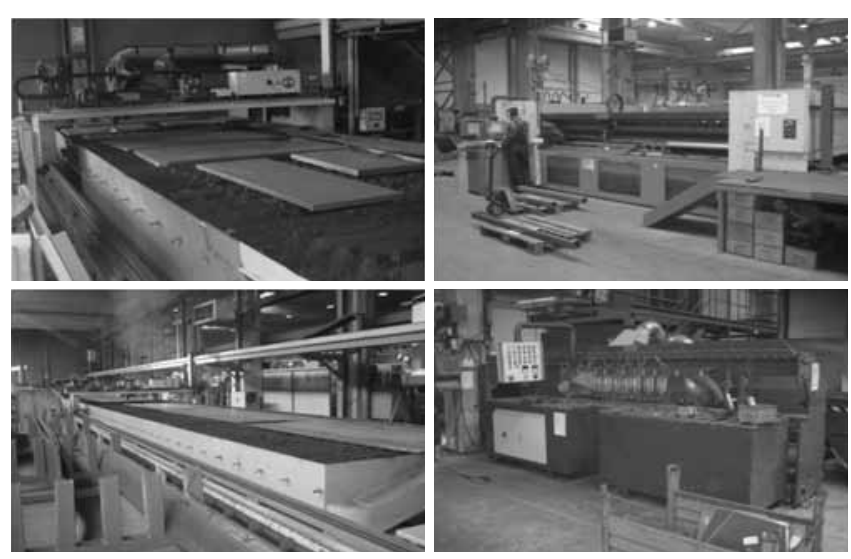

Rys. 1. Stanowiska przemysłowe do cięcia blach

Fig. 1. Industrial applications for plates cutting

\section{Pomiary twardości}

Twardość badanych krawędzi przeprowadzono metodą Vickersa na mikrotwardościomierzu Future - Tech FM 700. Wartości średnie pomierzonych twardości przedstawiono w tablicy III i na rysunku 2. 
HV0,5

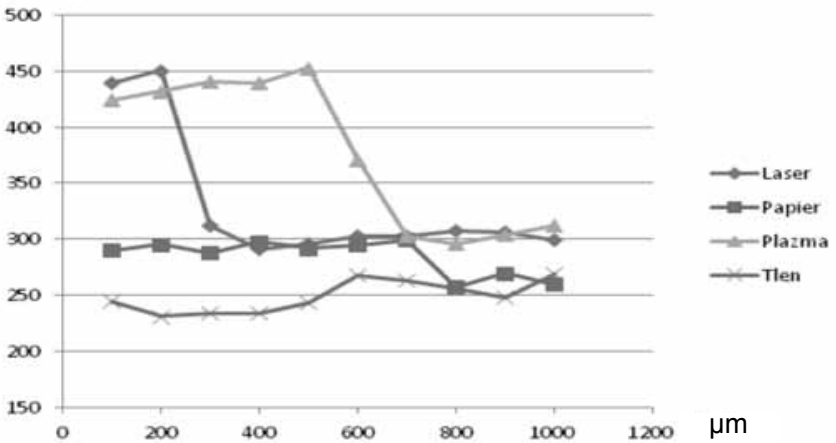

Rys. 2. Rozkład twardości krawędzi ciętej w zależności od metody cięcia Fig. 2. Hardness distribution in cut edge for various cutting methods

Tablica III. Twardość HV0,5 po cięciu blachy S690QL Table. III. Hardness HV0,5 after S690QL plate cutting

\begin{tabular}{|c|c|c|c|c|}
\hline Odległość od czoła & \multicolumn{4}{|c|}{ Twardość HV0,5 (wartości średnie) } \\
\hline$\mu \mathrm{m}$ & $\begin{array}{c}\text { Wiązka } \\
\text { laser }\end{array}$ & $\begin{array}{c}\text { papier } \\
\text { ścierny }\end{array}$ & $\begin{array}{c}\text { plazma } \\
\text { powietra }\end{array}$ & $\begin{array}{c}\text { tlenowo- } \\
\text { gazowe }\end{array}$ \\
\hline 100 & 439,1 & 290,4 & 424,4 & 244,0 \\
\hline 200 & 450,2 & 295,1 & 431,6 & 231,0 \\
\hline 300 & 312,5 & 287,7 & 439,9 & 233,8 \\
\hline 400 & 290,7 & 297,5 & 438,8 & 233,8 \\
\hline 500 & 295,6 & 291,7 & 452,6 & 243,0 \\
\hline 600 & 303,0 & 294,3 & 371,0 & 267,3 \\
\hline 700 & 303,1 & 299,6 & 303,2 & 262,7 \\
\hline 800 & 307,2 & 257,2 & 295,9 & 256,3 \\
\hline 900 & 305,8 & 269,5 & 304,2 & 248,1 \\
\hline 1000 & 299,5 & 259,7 & 311,7 & 269,1 \\
\hline
\end{tabular}

\section{Badania metalograficzne}

Celem przeprowadzonych badań metalograficznych było określenie kształtu i szerokości strefy wpływu ciepła oraz zmian strukturalnych zachodzących na badanych krawędziach w zależności od metody cięcia.

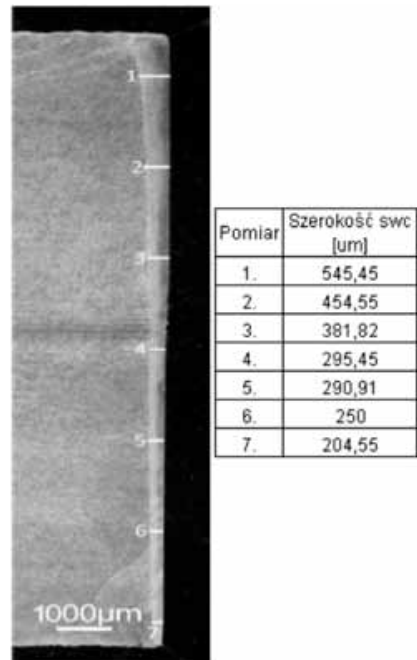

Rys. 3. Kształt i szerokość SWC krawędzi ciętej wiązką laserowa Fig. 3. The shape and width of HAZ in the edge after laser beam cutting
Rys. 4. Kształt i szerokość SWC krawędzi ciętej plazmą powietrzną Fig. 4. The shape and width of HAZ in the edge after plasma cutting

$\mathrm{Na}$ rysunkach $3 \div 6$ przedstawiono kształt i miejsca pomiaru szerokości stref wpływu ciepła, natomiast na rysunku 7 pokazano mikrostrukturę ciętego materiału z naniesionym dodatkowo rozkładem twardości.

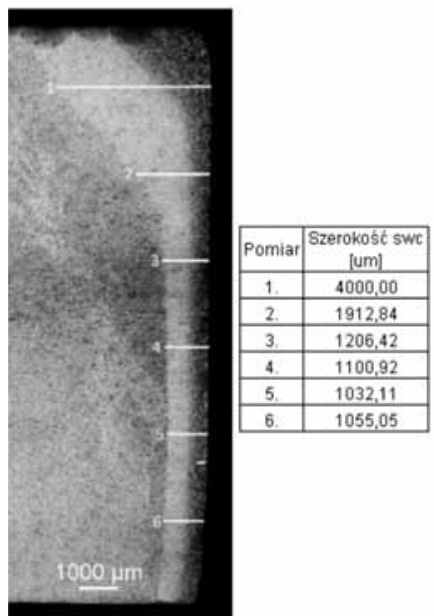

Rys. 5. Kształt i szerokość SWC krawędzi ciętej tlenem Fig. 5. The shape and width of HAZ in the edge after oxygen cutting

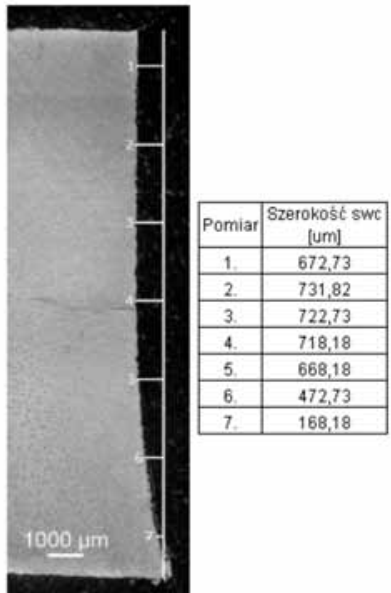

Rys. 6. Kształt krawędzi ciętej papierami ściernymi

Fig. 3. The shape in the edge after abrasive paper cutting
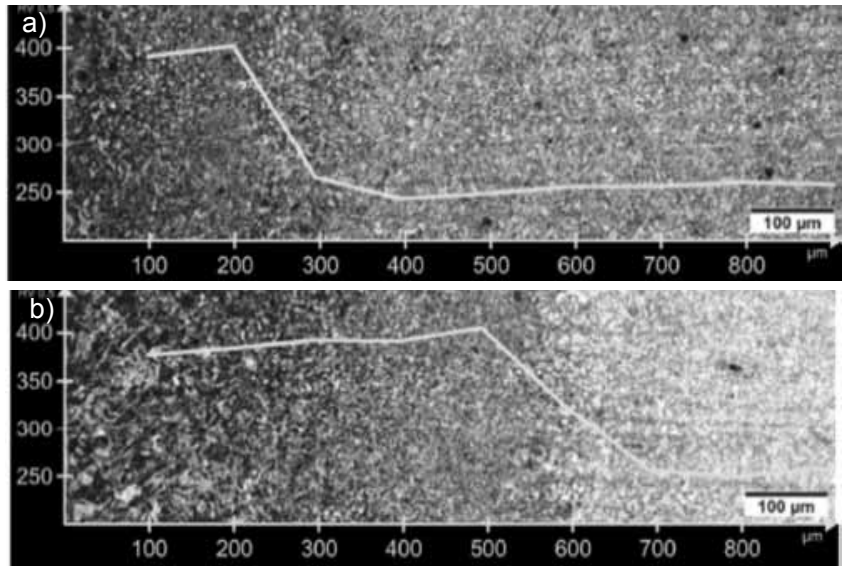
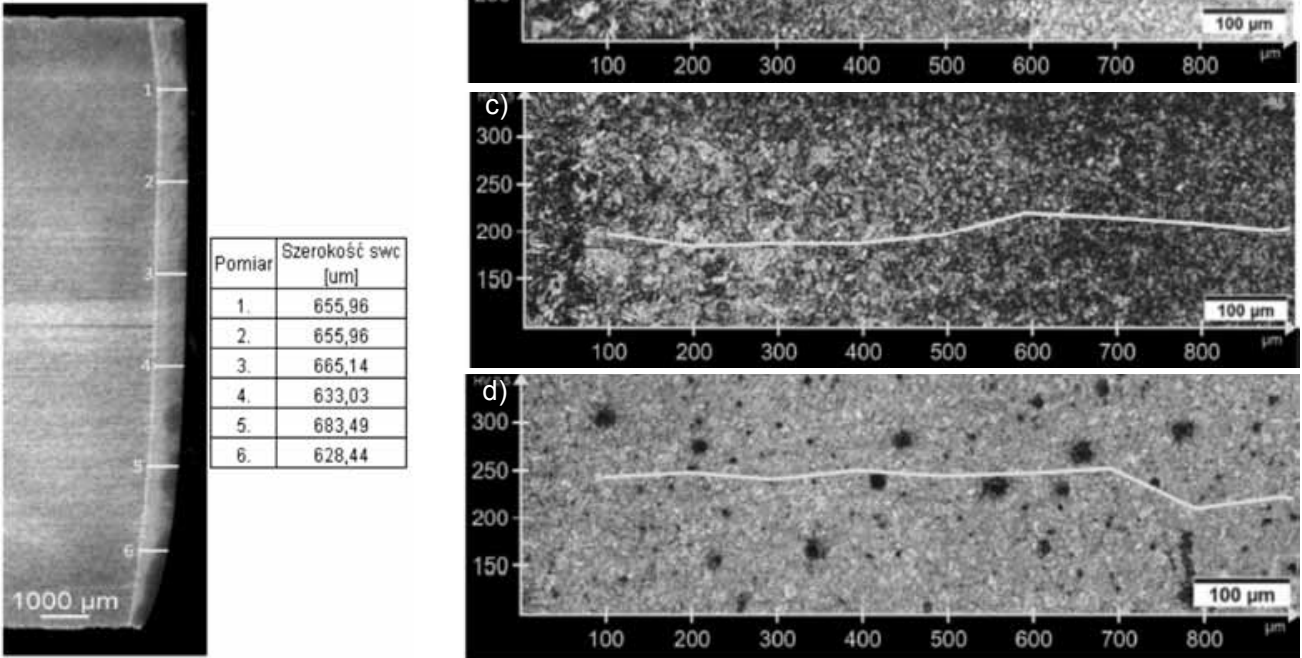

Rys. 7. Zmiany struktury i rozkład twardości krawędzi ciętych w zależności od metody cięcia: a) wiązką laserową; b) plazmą powietrzną; c) $\mathrm{C}_{2} \mathrm{H}_{2}-\mathrm{O}_{2}$; d) papierami ściernymi

Fig. 7. Structure and hardness change in cut edge for various cutting method: a) laser beam, b) plasma, c) $\mathrm{C}_{2} \mathrm{H}_{2}-\mathrm{O}_{2}$; d) abrasive papers 


\section{Analiza wyników badań}

Badania metalograficzne ujawniły zmienną, w zależności od metody cięcia, szerokość strefy wpływu ciepła. Najbardziej zmienna i szeroka strefa wpływu ciepła występuje przy cięciu tlenowym, gdzie szerokość SWC wynosi od $4 \mathrm{~mm}$ przy górnej płaszczyźnie cięcia do ok. 1,02 mm przy dolnej płaszczyźnie cięcia.

Plazma powietrzna ujawnia $\mathrm{w}$ miarę jednakową strefę wpływu ciepła o szerokości ok. 0,65 mm.

W przypadku cięcia wiązką laserową obserwuje się najmniejszą szerokość strefy wpływu ciepła o wymia-

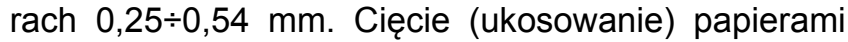
ściernymi nie uwidacznia strefy wpływu ciepła.

Badania mikroskopowe oraz pomiary twardości wykazały znaczące zmiany strukturalne i związane z tym zmiany twardości krawędzi ciętej.

Największe utwardzenia krawędzi ciętej uzyskano przy blachach ciętych plazmą powietrzną i wiązką laserową. W przypadku plazmy powietrznej utwardzenie krawędzi osiągnęło wartość maksymalną 452 HV0,5 na głębokości ok. 0,6 mm. Po przekroczeniu głębokości $0,7 \mathrm{~mm}$ nastąpił spadek twardości do ok. 280 HV0,5, odpowiadającej twardości materiału podstawowego. Ponadto przy powierzchni cięcia powstała struktura bainityczna o stosunkowo dużym ziarnie, przechodząca $\mathrm{w}$ drobnoziarnistą strukturę ferrytyczno-bainityczną o nieco mniejszej twardości.

Cięcie wiązką laserową spowodowało również miejscowe utwardzenie krawędzi ciętej powyżej 450 HV0,5, przy uwidocznionej strukturze bainitycznej na głębokości ok. 0,25 mm, przechodzącej w rozdrobnioną strukturę ferrytyczno-bainityczną.

Cięcie tlenem nie wykazuje utwardzenia w strefie wpływu ciepła, jednak duża ilość ciepła występująca $w$ tej metodzie powoduje bardzo duży rozrost ziarna, powodujący spadek właściwości plastycznych krawędzi ciętej.

\section{Podsumowanie}

Przeprowadzone badania wykazały, że aby spełnić wymagania PN-EN 1090-2, należy oprócz badań jakości krawędzi ciętej wg EN ISO 9013 dokonać również pomiaru twardości krawędzi i szerokości strefy wpływu ciepła.

Jakość powierzchni materiałów po cięciu termicznym jest opisana za pomocą dwóch podstawowych wartości charakterystycznych, tj.:

- tolerancji prostopadłości lub nachylenia, u;

- średniej wysokości profilu, Rz5.
Dodatkowo mogą być stosowane następujące wartości charakterystyczne:

- odchyłka cięcia, n;

- wielkość topienia górnej krawędzi, r;

- możliwość wystąpienia żużla lub stopionych kropli na dolnej krawędzi cięcia.

Każda z tych metod wprowadza do krawędzi ciętej określoną ilość ciepła, która powoduje zmiany strukturalne krawędzi ciętej, dające niekiedy zbyt duże utwardzenia tej krawędzi, co może być przyczyną odrzucenia wybranej metody cięcia w procesie wytwarzania.

\section{Literatura}

[1] Banasik M., Dworak J.: Cięcie i spawanie laserem $\mathrm{CO}_{2}$. Przegląd Spawalnictwa 8-10/2002.

[2] Cool waterjet process heats up cutting market. Welding Desing and Fabrication, November 2000.

[3] Hidden S., Buhler B.: The Great Debate: Plasma or Oxyfuel? Welding Journal, March 2005.

[4] Górka J., Krysta M.: Jakość cięcia stali obrobionej termomechanicznie plazmą powietrzną, laserem i strumieniem wody. Przegląd Spawalnictwa 8/2007.
[5] PN-EN 1090-2. Wykonanie konstrukcji stalowych i aluminiowych. Część 2: Wymagania techniczne dotyczące konstrukcji stalowych.

[6] EN ISO 9013. Cięcie termiczne - Klasyfikacja cięcia termicznego - Specyfikacja geometrii wyrobu i tolerancji jakości.

\section{W następnym numerze}

W następnym numerze opublikowane zostaną artykuły zgłoszone na III Naukowo - Szkoleniową Międzynarodową Konferencję Natryskiwania Cieplnego pt. „NATRYSKIWANIE CIEPLNE - TECHNOLOGIA XXI WIEKU" w Kielcach, 19-21 września 2012 r. 